\title{
Review: Grass-based dairy systems, data and precision technologies
}

\author{
L. Shalloo ${ }^{1 \dagger}, M_{.}$O' Donovan ${ }^{1}$, L. Leso ${ }^{2}$, J. Werner $^{3}$, E. Ruelle ${ }^{1}$, A. Geoghegan ${ }^{1}$, L. Delaby ${ }^{4}$ \\ and N. O'Leary ${ }^{1}$
}

\begin{abstract}
${ }^{1}$ Animal \& Pastureland Research and Innovation Centre, Moorepark, Fermoy, Co. Cork, Ireland; ${ }^{2}$ Department of Agricultural, Food and Forestry Systems, University of Florence, 50145 Firenze, Italy; ${ }^{3}$ Institute for Agricultural Engineering, University of Hohenheim, 70599 Stuttgart, Germany; ${ }^{4}$ INRA, AgroCampus Ouest, UMR Physiologie, Environnement et Génétique pour l'Animal et les Systèmes d'Elevage, 35590 Saint-Gilles, France
\end{abstract}

(Received 17 March 2018; Accepted 4 September 2018; First published online 22 October 2018)

Precision technologies and data have had relatively modest impacts in grass-based livestock ruminant production systems compared with other agricultural sectors such as arable. Precision technologies promise increased efficiency, reduced environmental impact, improved animal health, welfare and product quality. The benefits of precision technologies have, however, been relatively slow to be realised on pasture based farms. Though there is significant overlap with indoor systems, implementing technology in grass-based dairying brings unique opportunities and challenges. The large areas animals roam and graze in pasture based systems and the associated connectivity challenges may, in part at least, explain the comparatively lower adoption of such technologies in pasture based systems. With the exception of sensor and Bluetooth-enabled plate metres, there are thus few technologies designed specifically to increase pasture utilisation. Terrestrial and satellite-based spectral analysis of pasture biomass and quality is still in the development phase. One of the key drivers of efficiency in pasture based systems has thus only been marginally impacted by precision technologies. In contrast, technological development in the area of fertility and heat detection has been significant and offers significant potential value to dairy farmers, including those in pasture based systems. A past review of sensors in health management for dairy farms concluded that although the collection of accurate data was generally achieved, the processing, integration and presentation of the resulting information and decision-support applications were inadequate. These technologies' value to farming systems is thus unclear. As a result, it is not certain that farm management is being sufficiently improved to justify widespread adoption of precision technologies currently. We argue for a user need-driven development of technologies and for a focus on how outputs arising from precision technologies and associated decision support applications are delivered to users to maximise their value. Further cost/benefit analysis is required to determine the efficacy of investing in specific precision technologies, potentially taking account of several yet to ascertained farm specific variables.

Keywords: big data, pasture, decision support, sensors, cost-benefit analysis

\section{Implications}

Precision technologies, big data and data analytics have the potential to revolutionise pasture based ruminant production systems. Integrating precision technologies, big data and data analytics through a needs driven approach to solve the key drivers of pasture based systems will maximise the return for any investment and will ensure that these technologies are integrated within the systems. The likely benefits include increased efficiency, reduced costs and reduced environmental burden. At the same time, integrated databases and data structures that allow robust

${ }^{\dagger}$ E-mail: Laurence.Shalloo@Teagasc.ie traceability and sustainability monitoring within systems can be developed.

\section{Introduction}

Increasing agricultural systems sustainability, resilience to internal and external shocks and meeting and surpassing increasing food safety standards is a key challenge to farmers, researchers and associated stakeholders. In addition, it has been estimated that the demand for animal-derived protein may double by 2050 (Henchion et al., 2017). This will require producers to maximise production efficiencies while minimising any negative environmental impacts. Many studies have reported that pasture based systems of milk 
production have a distinct advantage over high input systems (Shalloo et al., 2004), with grazing systems associated with greater global sustainability, increased product quality, improved animal welfare and increased labour efficiency (O'Brien et al., 2012). It is also desirable to increase efficiency and sustainability in pasture-based systems. It is thus crucial that any farm investment strategy will increase the profitability of the farm business. In particular, a focus on increasing output through increased pasture growth and utilisation is associated with profitability (Shalloo et al., 2011). There is significant potential for improvement in efficiency even within well-developed pasture based systems such as Ireland (Creighton et al., 2011; Kelly et al., 2013) as well as other countries (MacDonald and Penno 1998; MacDonald et al., 2010).

There is significant interest in the application of precision technologies and information computer technologies in general in agriculture. Precision technologies in farming promise increased efficiency, improved product quality, reduced environmental impact and overall improvements in animal health and welfare. The promised benefits of precision technologies have been slow to be on dairy farms (Steeneveld et al., 2015). This has been more pronounced on grass-based systems. There are pasture specific challenges in addition to challenges common to pasture and non-pasture based contexts. In pasture based systems, there are additional costs of connectivity across large grazing platforms. The lower global value of the pasture based market relative to say indoor dairy systems or arable, for example, may reduce the interest from entrepreneurs and technology companies. A tendency towards lower capital expenditure in pasture based systems is also likely to play a role (Table 1). Despite this, technological innovation is required to support pasture based systems along with the adaptation of technologies already deployed in indoor systems. This review focusses on precision technologies within pasture based systems where the ultimate aim is to feed the animal with the available feed through synchronising the animal feed demand with the feed available in order that grass intake is maximised and grass wastage is minimised, ultimately increasing the precision in which the dairy cow is fed.

In order to complete a comprehensive review of precision technologies in grass-based dairy systems, there were five key areas identified. Although not exhaustive, these are key features affecting precision technologies and their impact on pasture based dairy systems. These are: (1) drivers of efficiency in grassland systems, (2) animal status and behaviour sensors, (3) sensors specific to grassland, (4) decision support system for pasture based systems and (5) precision technologies appropriateness and farm attributes. Then a paradigm is introduced for use in the pasture based precision technology adoption called 'Needs driven precisions technology development'. Finally, the key points of this paper are summarised in the conclusions including recommendations for future development of technologies on pasture based systems. In the remainder of this introduction, the current and potential importance of pasture based systems are outlined.

In the past 20 years, European production systems have moved away from grass-based systems into more high-cost and intensive systems. Though traditionally prevalent in areas such as the lowland of north western Europe, grazing is in competition with maize and renewable energy systems (Taube et al., 2014) . Despite grazing's strong economic and environmental potential, this potential is restrained by a lack of expertise and path dependency over the last century which has driven most European farms towards indoor and all yearround calving systems. Concentrate prices have for generally remained low and parts of Europe have built production systems based on high concentrate feed input. Many countries have now adopted a flat monthly milk production curve - with year-round calving as the norm. Feed sources have moved from grass to conserved feed stocks, mainly silage from either grass or maize. Such feeds (maize) need to be supplemented with high protein content balancers increasing costs. For these reasons, many parts of Europe do not have grass as the main feed source in livestock systems. Grassland and its utilisation is likely generally undervalued and underutilised across Europe. However, aiming to improve sustainability and economic resilience, there are movements by some back to increasing grassland utilisation (e.g. Campina/Friesland milk price bonus) (Van den Pol-van Dasselaar et al., 2018).

Increasing the efficiency and sustainability of pasture based systems is thus desirable to make grazing even more competitive, especially in areas where the pasture based system is currently a niche production model. In grassland

Table 1 The main differences between grazing and indoor systems

\begin{tabular}{ll}
\hline \hline Grazing systems & Indoor systems \\
\hline Grazing utilisation based & Conservation based (harvesting/zero grazing) \\
More than 200 days at grass & 0 to 100 days at grass \\
Medium output milk production per cow & High output milk production per cow \\
Low fixed and variable cost & High fixed and variable cost \\
Minimum to low building investment & High levels of building and slurry storage investment \\
Machinery - minimum/high contractor usage & Machinery - high requirement/little contractor usage \\
Labour flexibility & Labour routine \\
Seasonal workload & Similar workload all year \\
Resilient system - more consistent margins irrespective of milk price & High risk system economically - exposed at low milk price \\
\hline \hline
\end{tabular}


systems, flexible approaches and adaptive management are common due to increased role of climate in daily management. There is also less focus on output per cow and more focus on lowering costs. Table 1 summarises the main system differences between grass and indoor milk production systems. Generally, grass-based systems have lower costs of production per unit product whereas indoor systems rely more on high volume and lower margin per unit. High cost systems and milk price volatility combine to result in dairy businesses that are not profitable when milk price is low, reducing medium and long-term viability.

\section{Drivers of efficiency in pasture based systems}

The relative cost of pasture as a feed source for livestock production compared with grass silage and concentrate was reported as 1:1.8: 2.4, respectively, by Finneran et al. (2010). The competitive advantage of grass-based milk production thus lies in the ability to utilise grazed grass as the major feed source, significantly reducing costs per unit of production. Maintaining and increasing the competitiveness of grassbased systems thus requires growing and utilising more grass per hectare and converting that grass as efficiently as possible into valued products.

A number of factors influence costs of production and farm profitability in grass-based systems. Overall pasture utilisation, grazing season length, overall pasture management and level of supplementation are all strongly associated with profitability (Shalloo et al., 2004; MacDonald et al., 2010; Läpple et al., 2012; Kelly et al., 2013; Ramsbottom et al., 2015; Hanrahan et al., 2018).

In addition to grass-based factors, cow health and fertility is also highly important. Across both pasture and high input total mixed ration based systems, the optimum calving interval is 365 days (Esslemont et al., 2001). However, the relative importance of cow fertility is greater in seasonal dairy production systems which are more common on pasture based systems compared with non-seasonal systems (Veerkamp et al., 2002; Shalloo et al., 2014). Within pasture based systems, synchronising the demand for feed with the growth patterns of pasture is mainly achieved by planning the calving pattern such that the peak herd feed demand is matched with peak grass growth (Shalloo et al., 2007). In grass-based systems, the effect of sub optimal calving interval is thus magnified as feed supply and demand can become misaligned.

Boichard (1990) highlighted that additional inseminations, veterinary and hormonal costs and a modification of current and subsequent lactations are also costs associated with sub optimal fertility. There are also indirect costs such as the reduction in expansion potential (scale inefficiency) and disease risks associated with purchasing stock (Shalloo et al., 2014). Suboptimal fertility will also lead to an extended calving period, increasing the labour requirements for monitors cows about to calve and associated management (Shalloo et al., 2014).

The four main costs associated with cow fertility are reduced grass utilisation efficiency, increased veterinary costs, increased culling (Esslemont et al., 2001) and increased labour costs associated with longer calving period.

Overall, there are two major drivers of efficiency in pasture based systems. These are grass utilisation and cow health, and in particular within cow health, fertility. These are thus the areas precision technologies should focus on to maximise value in grass-based systems and sensors on the animal and sensors to measure grass can facilitate improved decision making.

Accurate grass growth and biomass measurement is one such area where significant adoption of existing technologies would likely be beneficial. Further development of existing technologies and the development of new technologies will allow for greater detail and inform pasture management through for example targeted use of inputs as is now common in arable contexts (Hanrahan et al., 2017). Understanding and monitoring animal's behaviour, how she interacts with her environment and how her behaviour changes during times of different physiological states is likely to further improve the animal part of the systems performance. Combining both information sources or collecting information about how individual animals interact with variation in grasslands and vice versa, how grasslands react to animals, may also be a possibility in the medium to long term.

\section{Animal status and behaviour sensors}

Cow behaviour such as movement, location, rumination and resting are of importance for herd management (Delagarde and Lamberton, 2015; Delagarde and Lemonnier, 2015) and heat detection is the most established use case of such information (Rutten et al., 2013). Several different approaches have been developed to measure various cow behaviours.

Accelerometers are a common sensor used on cows and can measure behaviours such as feeding and rumination. The position of those systems on a cow varies with head, neck, ear and leg-mounted devices available (Bikker et al., 2014; Borchers et al., 2016). Acceleration measured by accelerometers, usually attached to the animal's legs, can be used to measure locomotion activity (e.g. RumiWatch pedometre (Alsaaod et al., 2015) or IceTag pedometre (Ungar et al., 2017)). These measurements can give an insight into different events (e.g. heats, health and behaviour, etc.) as increased activity can be associated with oestrus events.

Other technologies for heat detection are mounting activity sensors including tail paint, scratch cards, KaMaRs (KaMaR) and HeatWatch (CowChips) (Holman et al., 2011). One of the most recent developments in using accelerometer data is in lameness detection with the IceTag3D ${ }^{\mathrm{TM}}$ (IceRobotics, Edinburgh, UK). They recently began offering lameness detection as function in late 2017 (IceRobotics, 2017).

As feeding behaviour differs when cows are grazing, the sensors which accurately measure feeding behaviour indoors are unlikely to be as effective with grazing cows. These 
Precision technologies in ruminant production systems

sensors may thus require adaption and recalibration for grazing cows. Most commercial sensors that are used on farms for measuring grazing behaviour use an accelerometer around the neck (e.g. Heattime ${ }^{\circledR}$ by SCR Engineers, Netanya, Israel (Molfino et al., 2017) or MooMonitor + ; Dairymaster, Tralee, Ireland (Werner et al., 2017)).

One system for research uses a pressure band sensor in a halter to detect jaw movements (Zehner et al., 2017). It is called the RumiWatch (Itin + Hoch GmbH, Liestal, Switzerland) and the recorded jaw movements are used to measure feeding behaviour (Werner et al., 2017). The RumiWatch is capable of measuring detailed grazing behaviour such as rumination chews and grazing bites as well as rumination and grazing times (Werner et al., 2017).

Understanding how an animal interacts with her environment helps to explain the individual animals grazing behaviour and will help to explain within paddock variation and its impact on performance. Cow localisation allows an analysis, spatial analysis of the individual animal to be completed. Recording grazing behaviour location and linking that to high resolution grass measurements could be useful for research and management purposes. There are already a number of techniques to determine animal position indoors. One such system is the Smartbow ear tag (Smartbow, Weibern, Austria). Smartbow works by triangulating the location of cow worn ear tags with low-frequency signals which are detected by multiple receivers in the barn allowing triangulation. It has been shown to have reasonable accuracy in determining cow location indoors (Wolfger et al., 2017).

It is also possible to localise animals via ultra-wideband technology (e.g. CowView; GEA Farm technologies $\mathrm{GmbH}$, Germany (Tullo et al., 2016)). In pasture based systems, the accurate measurement of the animal's position used to be limited to global position system (GPS) based tracking systems (Williams et al., 2016), but other approaches that are less burdensome on batteries are being developed (e.g. using ground based triangulation with multiple base stations).

Lameness is also particularly relevant in larger pasture based dairy farms where cows may have to walk large distances between the milking parlour and pasture. Accelerometer based lameness detection discussed above is the most prominent. However, there are other approaches also in development such as walkover systems (e.g. StepMetrix ${ }^{\circledR}$; BouMatic, Madison, WI, USA) and camera based systems (Viazzi et al., 2014; Fischer et al., 2015). Camera based systems also have the potential for other uses such as automated body condition scoring (Halachmi et al., 2013; Fischer et al., 2015; Spoliansky et al., 2016). To date, two automated body condition scoring systems have been made commercially which use image analysis based approaches (Delaval, Tumba, SE and Ingenera SA, Cureglia, CH).

Van De Gucht et al. (2017) found in a survey that a sensor attached to the cow was preferred by Flemish farmers, followed by a walkover system and a camera system. Some studies already demonstrate positive results for automated lameness detection, but in many cases, the animal must be critically lame to be detected. Beer et al. (2016) showed that it is feasible to differentiate lame cows ( $>2.5$ locomotion score) (1-5 scale) from non-lame cows with data gathered by a pedometer (RumiWatch). Despite significant development work and activity over many years, a September 2018 search of the literature for an independent validation of a commercially available lameness detection system returned no such studies.

\section{Sensors specific to grassland}

Focussing on pasture based milk production systems, the application potential of sensor technology is increasing. We now review sensor technologies that can aid grassland management including spectral sensors (terrestrial and remote), digitally enabled mechanical plate metres and ultrasonic sensor based plate metres.

Grassland farmers that rely on pasture as their primary feed source require accurate real-time measurement of pasture herbage mass and quality to optimise grazing and nutrition management. Each additional $1000 \mathrm{~kg}$ increase in pasture utilisation per hectare was recently reported to be associated with €173 greater profit per hectare (Hanrahan et al., 2018).

With other crops such as maize and soybean, sensors are now routinely being placed in fields measuring the microclimate, spectral characteristics and small-scale differences in soil fertility to help improve crop management and productivity (Wolfert et al., 2017). However, sensors to aid pasture management and increase utilisation are still in development and with a few exceptions (e.g. Bluetoothenabled plate metres), are not yet commercially available. As pasture utilisation is a key driver of profitability in such systems (Hanrahan et al., 2018), these sensors, like pasture growth measurement tools, may offer particularly high returns to pasture based producers.

Examples of technology that enable improved pasture utilisation include digitally enabled plate metres which streamline and automate aspects of collecting the data required to generate pasture budgets (French et al., 2015). Distance measurement in the plate height is usually generated via ultra/micro-sonic sensors which measure the height of the plate resting on the canopy (Moeckel et al., 2017). These have an added benefit in that the operator skill required is much less than for example visual assessments. Given the importance of measurement in managing and increasing pasture utilisation, plate metres can offer significant benefits for relatively modest capital investments. When combined with GPS localisation and app or server connectivity, this potentially allows significant and novel functionality.

A similar approach to a plate metre is to measure the height of the pasture canopy. However, while a plate metre presses down on grass to variable degrees based on grass density, this approach measuring the canopy height is less sensitive to pasture density and so less sensitive to herbage biomass.

Although plate metre approaches provide a good estimate of biomass, commercially available tools do not currently 
assess pasture quality. Be the platform handheld, drone or satellite-based, spectral analysis (terrestrial or remote) is a potential candidate approach for the estimation of grass quality and would be a potentially quick and efficient alternative to lab-based assessments (Sibanda et al., 2016). If successful, such information could allow farmer to allocate grass based on the feed quality available rather than specifically on a dry matter basis.

A common approach is to develop particular wavelengths to create indices such as Normalised Difference Vegetation Index (NDVI) which estimate if vegetation is present or not by assessing the ratio of red and near-IR wavelengths. The photosynthetically active range is between 400 and 700 nanometres which appear relatively dark in vegetation. Above 700 nanometres appears relatively bright as plants reemit these wavelengths. Strong absorption above 700 nanometres would not aid photosynthesis and would result in overheating.

The challenges facing spectral approaches include background soil effects, atmospheric effects, grazing impact and heterogeneity of species and variation in pasture growth stages/proportion of senescent material in the canopy which disproportionately influence spectral data (Moeckel et al., 2017). Further to this, most studies have focussed on measuring pastureland biomass in tropical savannahs via remote satellite sensing with less focus on temperate pasturelands (Moeckel et al., 2017).

Moeckel et al. (2017) reported combining an ultrasonic sensor to measure grass canopy height, a handheld hyperspectral sensor data and satellite-derived spectral data. They found that the best predictions of biomass were early in the grazing season when pastures were more homogenous. As grazing season continued, issues such as pasture refusal post grazing resulted in variability in the sensor outputs which could not be accounted for when predicting biomass. The accuracy values achieved with biomass indicate that further development is required before practical application in pastureland management are possible (maximum $R^{2}=0.52$ ).

Successful non-satellite based spectral approaches to estimate pasture quality in temperate intensively managed pasturelands were not found in a search of the literature. There has been some progress using satellite data to estimate pasture biomass using Synthetic Aperture Radar. One study of Irish pasture found that grass biomass could be predicted with an $R^{2}$ of up to 0.75 based on this approach (Ali et al., 2017). This prediction was only achieved periodically when conditions were right in 'coherent' paddocks. Highly coherent paddocks tended to have low biomass after mowing. Factors, such as wind flattening, tall grass and grazing/mowing complicated the interpretation of the satellite data, especially as biomass increased.

There is potential for technologies to streamline and potentially automate the collection of pasture data such as biomass and quality, calculate pasture availability and to integrate the data with other sources, for further use for example (French et al., 2015). Improving fertiliser utilisation by targeting the areas with the most requirement based on previously recorded yields or spectral analysis, as well as protecting water courses are both potential applications in combination with GPS enabled spreaders.

There is the potential for precision technologies to significantly contribute to pasture management, and thus increase pasture utilisation. However, there are significant technical challenges to be overcome for that to occur. This is particularly true with regards to grass quality.

\section{Decision support systems for pasture based systems}

Decision support systems (DSS) are available for systems that utilise grass as a major source of feed for dairy cows. Such technology facilitates the improved grassland management, delivering tangible benefits in terms of grass supply, quality and utilisation and ultimately profitability. The main features of the pasture management tools include the grass wedge, grass budget and the spring and autumn rotation planners. Some DSS use historical grass growth data to estimate pastureland production capacity and aid long-term management decisions like determining the most suitable stocking rates and plan paddock reseeding. These management decisions have been found to be strongly associated with the economic performance of pasture based dairies (Kennedy et al., 2007; Shalloo et al., 2011; McCarthy et al., 2013). One recent innovation has been to focus on the number of grazings achieved on individual paddocks. This is now a key performance indicator for Irish grassland systems. Such tools assist farmers in short- to medium-term grass management (MacDonald et al., 2010).

Smartphone, and to a lesser extent personal computer, based applications are the platforms used. These provide greater flexibility to the user. Furthermore, internet-based architecture enables the collation of large quantities of data in central databases. This extends the data usefulness beyond farm level. Data collected on a wide number of farms can be used to benchmark performance of a single operation, but also for research purposes (e.g. animal and plant genetics, precision nutrition) and policy formulation (Hanrahan et al., 2017).

One example is Pastur'Plan, a new tool available in France (Delaby et al., 2015) which combines two concepts. The first one is adapted from the Grass Wedge and the second one describes the balance between grass growth and demand according to different grazing options on a paddock by paddock basis. Pastur'Plan takes into account herd size and supplementation fed to calculate the grass demand of the herd. The weekly grass growth profile can be changed and updated by the user allowing the calculation of the grass available. Pastur'Plan helps the user (farmer or advisor) to anticipate the utilisation of their grass on farm at the paddock level.

This facilitates the testing of different scenarios to optimise grass utilisation. The objective of this tool is to stimulate 
better grazing management, improve grass utilisation and provide more confidence in grazing systems.

Another DSS in the area of pasture research is PastureBase Ireland (PBI) (Hanrahan et al., 2017). It builds on the concept of citizen science where data are collected by individuals while they go through their everyday lives (Conrad and Hilchey, 2011). Citizen science has proved successful in the past in many countries, forming the bedrock of biological recording in various large research projects, particularly in ecology and environmental sciences.

In the case of PBI, pastureland farmers are the citizen scientists collecting the pasture data that feed into a new research programme. This is being facilitated through the creation of discussion forums within the PBI system. These discussion forums allow for the communication and organisation of research and technology initiatives, increasing farmer engagement in grassland research.

Holistic farm solutions derived from the integration of sensor data, data interrogation and providing information to the end users through an appropriate medium and time framework are increasingly feasible (Figure 1; Shalloo et al., 2018). However, to date, literature about decision making with precision technologies is sparse, especially regarding pasture based dairy systems.

Not specifically related to pasture but related are animal health databases. Veterinary use of medicines (especially antibiotics) is regulated in most countries with the recording of information regarding diagnosis and treatments being a common requirement. The quantity and type of medicines administered to individual cows could potentially be stored in a central database. However, in most countries, although this information has been systematically recorded on paper, it generally has not been recorded electronically and has not been collated centrally (Egger-Danner et al., 2012). One example country where a significant effort has been put into standardising and aggregating animal health data relating to dairy cows is Austria. In Austria, the recording of animal health treatments was made a legal requirement in 2002 but the form and coding of this recording were not standardised or aggregated until 2006 (Egger-Danner et al., 2012).

In relation to animal genetics, there are a number of databases that are critical to increasing herd genetic merit (e.g. International Committee for Animal Recording Interbull database; Irish Cattle Breeding Federation database). Such data can be collected by public companies or associations such as in Ireland and Italy but also by private genetic companies. Information regarding animal performance including milk yield, fertility, longevity, animal health, administered treatments, calving, etc. is routinely recorded. Precision technologies offer significant potential to inform breeding programmes through the automated collection of phenotypic traits such as activity and behaviour, which may be of economic value to select for. An example might include monitoring activity data that is collected by devices on individual animals as well as diagnoses of illness. Many of the traits that these devices collect information on are heritable, and it is desirable to record it to improve future breeding programmes.

The robustness of data collected by sensors is still perceived as a priority and thus most research focusses on sensing accuracy and systems validation. Decision making remains pivotal, but underdeveloped, to the successful application of precision technologies. Decision support and automation is the basis of value creation from precision

\begin{tabular}{l|l|l|l} 
1. Technique & $\begin{array}{l}\text { 2. Data } \\
\text { Interpretation }\end{array}$ & $\begin{array}{l}\text { 3. Integration of } \\
\text { Information }\end{array}$ & 4. Decision making \\
\hline
\end{tabular}

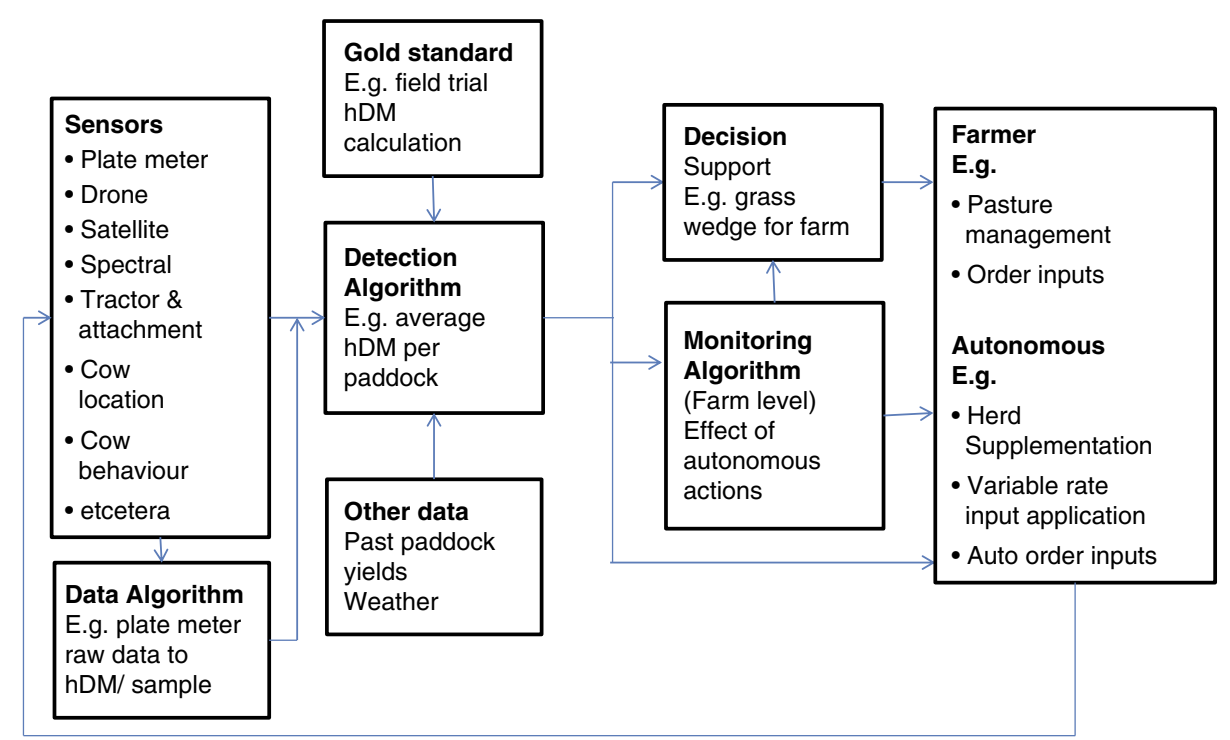

Figure 1 Schema of stages of decision making and the use of sensor information in dairy farm management. Adapted from cow focussed (Rutten et al., 2013) to grass focussed. $\mathrm{hDM}=$ herbage dry matter. 
technologies for the farmer (Hostiou et al., 2017). Though accurate collection of more data is a dominant theme in precision technology, using and combining extant sources of data better through improve decision support and automation should also be a priority.

\section{Precision technologies appropriateness and farm attributes}

For farmers, it is difficult to accurately estimate the economic benefit for most technologies in advance of adoption. The risk of expensive technologies delivering poor financial returns to farmers is significant. One of the few studies that investigated this found that sensors did not deliver a discernible return to Dutch dairy farmers between 2008 and 2013 (Steeneveld et al., 2015). They compared three categories of dairy farms, conventional milking systems with no sensor technology, conventional milking systems with sensors (usually cow activity sensors) and automatic milking systems (AMS). The AMS systems were significantly less profitable than conventional farms with sensors with profit per $100 \mathrm{~kg}$ of milk dropping from $€ 3.86$ to $€ 1.31$.

The reduction in profit was mostly attributable to higher depreciation costs and, contrary to expectations, only modest recorded reductions in labour costs (Steeneveld et al., 2015). They found that no statistically significant difference in productivity (before finance costs) could be discerned between conventional systems before and after installing sensor systems. This indicates, on average, a neutral or very modest return on investment for the average farmer in the study.

Sensor technology has advanced since that study and likely reduced in cost significantly. Increasing performance of activity sensors (Steeneveld et al., 2017; Werner et al., 2017) and the application of advanced techniques such as machine learning have likely added additional value (Borchers et al., 2017). Returns may have also improved as technologies and knowledge about them improve.

There may, however, be significant variation in the returns achieved. This variation can be attributed to variation in farms, farmers and technologies invested. Consequently, there will continue to be a proportion of farmers investing in technologies which are not achieving good financial returns. Replicating Steeneveld et al.'s (2015) study in both indoor and pasture-based dairying systems would be advantageous.

Such a study could also establish the drivers of variation in investment returns and aid the provision of advice to farmers. Advice and knowledge arising could have multiple applications. First, it would guide vendors to better target their research, development and marketing of technologies. Second, farmers would have more insight as to which combination of technologies and farm situations deliver the best returns.

Why some Dutch dairy farmers benefited financially whereas others did not, from investing in precision technologies (Steeneveld et al., 2015), has to date not been investigated. Farmers will be rightfully cautious about technologies until this is clarified. In being cautious, they will likely be overlooking technologies which offer significant economic benefits. This is because these beneficial technologies are currently hard to distinguish from those that do not. This is a major issue as the adoption rate of precision technologies remains low (Steeneveld et al., 2017). In light of this, increased knowledge of the drivers of adoption rates can also be used to increase average returns.

While the drivers of good returns (as opposed to just adopting or not) from technology investment are relatively unknown. There is, however, a wealth of literature on the motivations of farmers to invest in a technology or adopt specific management practices which also like to predict returns (Garforth et al., 2006; Garforth, 2010; Jones et al., 2016).

Advisory services may wish to consider developing knowledge and expertise so that independent sources of advice and resources are available farmers to improve the returns farmers make from investments, and so drive the adoption of beneficial technology. These could include centralised information sources on technology efficacy, standard operating procedures for using the technology and budgeting tools designed with technology investment appraisal in mind (O'Leary et al., 2018).

There is a risk that technologies developed in other contexts such as indoor systems will be marketed to farmers in pasture based systems where their utility is marginal and their efficacy reduced. A focus on technologies that meet clear needs at the farm level such as pasture quality assessment is advisable.

We venture that the key need of pasture based farming systems is transforming sustainability from a broad illdefined concept to a clear and measurable construct. Within sustainability, we further specify the following as priority areas for precision technology research, development and innovation: labour shortages (automation/labour efficiency), management ability (improving farmer capacity for an increasingly complex technology reliant role), economic resilience (adding value to products, reducing costs and increasing efficiencies) and environmental, animal health and welfare benchmarking.

We further introduce the concept of 'Need Driven' development to agriculture precision technologies (Kruger and Cross, 2006). These are a set of principles to guide and expedite the achievement of precision technologies potential in pasture based livestock ruminant production systems. Need driven technologies are solutions that are delivered in ways that are comprehensible and relevant to the farmer. In addition, they generate data that can inform major research programmes (e.g. animal genetics, grass genetics and performance evaluation). We contrast this to 'Solution Driven' development where developers start with a technology (solution) and try to find additional applications for the technology. Solution based approaches are potentially valuable but are not necessarily focussed on the areas of most value to farmers.

Needs driven precision technology should in contrast meet pressing needs such as providing mechanisms to quantify the 
sustainability of pasture based ruminant production and increase farm profitability. These needs can be addressed through the integration of existing databases, capturing new data and the application of best practice in data science to generate the most value from the data.

Technological solutions which can increase the utilisation of pasture and the productivity and fertility of seasonal calving herds are likely to add significant value to pasture based systems. These should provide real benefits in profitability, sustainability and resilience by providing informed, real-time solutions to the farmer through an appropriate medium.

In order for big data and smart technologies to realise their potential in grassland agriculture, there is a requirement for the different industry stakeholders to work together and to develop business models that facilitate and encourage the different stakeholders to integrate their solutions within an overall platform.

Although many researchers and companies already embrace approaches similar to Need Driven development, some do not, and by naming and defining this paradigm in a grass-based context - we hope it may add value and clarity.

\section{Conclusions}

This review focussed on precision within pasture based systems. Precision technologies offer significant potential to increase efficiency, reduce costs and labour, increase sustainability, improve sustainability verification and raise animal welfare standards of pasture based systems of milk production. The integration of sensor data, collated within centralised databases enriched with existing data and analysed for specific end use requirements, is recommended. Outputs provided through appropriate media and in realtime fashion will alter the use of these technologies in pasture based farming.

A key shortcoming to date in this area is the failure to add value to data collected as the focus has been on accuracy. Farmer's time is limited and their skills and capabilities are variable. Designing tools and products with these factors in mind will improve tools impact. For big data and smart technologies to realise their potential in agriculture, there is a requirement for the various industry stakeholders to work together to create a consensus regarding the main industry needs. This will facilitate the development of platforms and infrastructure that can maximise the potential of precision technologies by meeting and addressing the most pressing needs. The key drivers of efficiency and profitability in pasture based systems are pasture utilisation and dairy cow fertility. Technologies that support grass utilisation and fertility have the greatest chance of delivering positive economic returns for farmers. For the industry as a whole, the most pressing needs in addition to farm profitability are sustainability assessments and sustainability management which technology is likely to facilitate and support.

\section{Acknowledgements}

The authors gratefully acknowledge funding provided by Science Foundation Ireland through the funded investigator programme and the PRECISIONDAIRY project.

\section{Declaration of interest \\ None.}

\section{Ethics committee \\ Not applicable.}

\section{Software and data repository resources}

None of the data were deposited in an official repository.

\section{References}

Ali I, Barret B, Cawkwell F, Green S, Dwyer E and Neumann M 2017. Application of Repeat-Pass TerraSAR-X staring spotlight interferometric coherence to monitor pasture biophysical parameters: limitations and sensitivity analysis. Institute of Electrical and Electronics Engineers Journal of Selected Topics in Applied Earth Observations and Remote Sensing 10, 3225-3231.

Alsaaod M, Niederhauser JJ, Beer G, Zehner N, Schuepbach-Regula G and Steiner A 2015. Development and validation of a novel pedometer algorithm to quantify extended characteristics of the locomotor behaviour of dairy cows. Journal of Dairy Science 98, 6236-6242.

Beer G, Alsaaod M, Starke A, Schuepbach-Regula G, Müller H, Kohler P and Steiner A 2016. Use of extended characteristics of locomotion and feeding behavior for automated identification of lame dairy cows. PLoS One 11, e0155796.

Bikker JP, Van Laar H, Rump P, Doorenbos J, Van Meurs K, Griffioen GM and Dijkstra J 2014. Technical note: evaluation of an ear-attached movement sensor to record cow feeding behavior and activity. Journal of Dairy Science 97, 2974-2979.

Boichard D 1990. Estimation of the economic value of conception rate in dairy cattle. Livestock Production Science 24, 187-204.

Borchers MR, Chang YM, Proudfoot KL, Wadsworth BA, Stone AE and Bewley JM 2017. Machine-learning-based calving prediction from activity, lying, and ruminating behaviors in dairy cattle. Journal of Dairy Science 100, 5664-5674.

Borchers M, Chang Y, Tsai I, Wadsworth B and Bewley J 2016. A validation of technologies monitoring dairy cow feeding, ruminating, and lying behaviors. Journal of Dairy Science 99, 7458-7466.

Conrad CC and Hilchey KG 2011. A review of citizen science and communitybased environmental monitoring: issues and opportunities. Environmental Monitoring and Assessment 176, 273-291.

Creighton P, Kennedy P, Shalloo L, Boland TM and O' Donovan M 2011. A survey analysis of grassland dairy farming in Ireland, investigating grassland management, technology adoption and sward renewal. Grass and Forage Science 66, 251-264.

Delaby L, Duboc G, Cloet E and Martinot Y 2015. Pastur'Plan: a dynamic too to support grazing management decision making in a rotational grazing system. Grassland in Europe 20, 200-202.

Delagarde R and Lemonnier JP 2015. Accuracy of the feedphones device for recording eating and ruminating times in dairy cows. Grassland in Europe 20, 203-205.

Delagarde R and Lamberton P 2015. Daily grazing time of dairy cows is recorded accurately using the Lifecorder Plus device. Applied Animal Behaviour Science 165, 25-32.

Egger-Danner C, Fuerst-Waltl B, Obritzhauser W, Fuerst C, Schwarzenbacher H, Grassauer B, Mayerhofer M and Koeck A 2012. Recording of direct health traits in Austria-experience report with emphasis on aspects of availability for breeding purposes. Journal of Dairy Science 95, 2765-2777.

Esslemont RJ, Kossaibati MA and Allcock J 2001. Economics of fertility in dairy cows. In Proceedings of Workshop - Recording and Evaluation of Fertility Traits in UK Dairy Herd, 19-20 November 2001, Edinburgh, UK, pp. 5-15. 


\section{Shalloo, O' Donovan, Leso, Werner, Ruelle, Geoghegan, Delaby and O'Leary}

Finneran E, Crosson P, Wallace M, O'Kiely P, Forristal PD and Shalloo L 2010 . Simulation modelling of the cost of production and utilizing feeds for ruminants on Irish farms. Journal of Farm Management 14, 95-116.

Fischer A, Luginbuhl L, Dellattre JM, Delouard S and Faverdin P 2015. Rear shape in 3 dimensions summarised by principle component analysis is a good predictor of body condition score in Holstein dairy cows. Journal of Dairy Science 98, 4465-4476.

French P, O'Brien B and Shalloo L 2015. Development and adoption of new technologies to increase the efficiency and sustainability of pasture based systems. Animal Production Science 55, 931-935.

Garforth C 2010. Motivating farmers: insights from social psychology. In Proceedings of the Annual Meeting-National Mastitis Council, Reading, UK, pp. 60-67. Retrieved 31 August 2018 from ftp://s173-183-201-52.ab.hsia.telus.net/ Inetpub/wwwroot/DairyScience/Extension/NMC\%202010\%20motivation\% 20Garforth.pdf.

Garforth C, McKemey K, Rehman T, Tranter R, Cooke R, Park J, Dorward P and Yates C 2006. Farmers' attitudes towards techniques for improving oestrus detection in dairy herds in South West England. Livestock Science 103, 158-168.

Halachmi I, Klopčič M, Polak P, Roberts DJ and Bewley JM 2013. Automatic assessment of dairy cattle body condition score using thermal imaging. Computers and Electronics in Agriculture 99, 35-40.

Hanrahan L, Geoghegan A, O'Donovan M, Griffith V, Ruelle E, Wallace M and Shalloo L 2017. PastureBase Ireland: a grassland decision support system and national database. Computers and Electronics in Agriculture 136, 193-201.

Hanrahan L, McHugh N, Hennessy T, Moran B, Kearney R, Wallace M and Shalloo $L$ 2018. Factors associated with profitability in pasture based systems of milk production. Journal of Dairy Science 101, 1-12.

Henchion M, Hayes M, Mullen A, Fenelon M and Tiwari B 2017. Future protein supply and demand: strategies and factors influencing a sustainable equilibrium. Foods 6, 53.

Holman A, Thompson J, Routly J, Cameron J, Jones D, Grove-White D, Smith R and Dobson $\mathrm{H}$ 2011. Comparison of oestrus detection methods in dairy cattle. Veterinary Record-English Edition 169, 47.

Hostiou N, Fagon J, Chauvat J, Turlot A, Kling-Eveillard K, Boivin X and Allain C 2017. Impact of precision livestock farming on work and human-animal interactions on dairy farms. A Review Base 21, 268-275.

IceRobotics 2017. COWALERT lameness detection highly commended. www. icerobotics.com. Retrieved on 28 June 2018 from http://www.icerobotics.com/ news/cowalert-lameness-detection-highly-commended/.

Jones PJ, Sok J, Tranter RB, Blanco-Penedo I, Fall N, Fourichon C, Hogeveen H Krieger MC and Sundrum A 2016. Assessing, and understanding, European organic dairy farmers' intentions to improve herd health. Preventive Veterinary Medicine 133, 84-96.

Kelly E, Shalloo L, Geary U, Kinsella A, Thorne F and Wallace M 2013. An analysis of the factors associated with technical and scale efficiency of Irish dairy farms. International Journal of Agricultural Management 2, 149-159.

Kennedy E, O'Donovan M, Murphy JP, Delaby L and O'Mara FP 2007. Effect of spring grazing date and stocking rate on sward characteristics and dairy cow production during mid lactation. Journal of Dairy Science 90, 2035-2046.

Kruger C and Cross N 2006. Solution driven versus problem driven: strategies and outcomes. Design Studies 27, 527-548.

Läpple D, Hennessy T and O'Donovan M 2012. Extended grazing: a detailed analysis of Irish dairy farms. Journal of Dairy Science 95, 188-195.

Macdonald KA, Glassey CB and Rawnsley RP 2010. The emergence, development and effectiveness of decision rules for pasture based dairy systems. In Proceedings of the 4th Australasian Dairy Science Symposium, 2010, Hamilton, New Zealand, pp. 199-209.

MacDonald KA and Penno JW 1998. Management decision rules to optimise milksolids production on dairy farms. New Zealand Society of Animal Production 58, 132-135.

McCarthy B, Pierce KM, Delaby L, Brennan A, Fleming C and Horan B 2013. The effect of stocking rate and calving date on grass production, utilization and nutritive value of the sward during the grazing season. Grass and Forage Science 68, 364-377.

Moeckel T, Safari H, Reddersen B, Fricke T and Wachendorf M 2017. Fusion of ultrasonic and spectral sensor data for improving the estimation of biomass in grasslands with heterogeneous sward structure. Remote Sensing 9 $1-14$
Molfino J, Clark CEF, Kerrisk KL and García SC 2017. Evaluation of an activity and rumination monitor in dairy cattle grazing two types of forages. Animal Production Science 57, 1557-1562.

O'Brien D, Shalloo L, Patton J, Buckley F, Grainger C and Wallace M 2012. A life cycle assessment of seasonal grass-based and confinement dairy farms. Agricultural Systems 107, 33-46.

O'Leary N, Ahrend A, McDonagh A, O'Brien B and Shalloo L 2018. A partial budgeting tool to assess investments in precision dairy technologies. In Proceedings of the European Grassland Federation General Meeting, Grassland Science in Europe, Sustainable Meat and Milk Production from Grasslands, 1721 June 2018, Cork, Ireland, pp. 810-812.

Ramsbottom G, Horan B, Berry DP and Roche JR 2015. Factors associated with the financial performance of spring-calving, pasture based dairy farms. Journal of Dairy Science 98, 3526-3540.

Rutten CJ, Veilthuis AG, Steeneveld W and Hogeveen H 2013. Invited review: sensors to support health management on dairy farms. Journal of Dairy Science 96, 1928-1952.

Shalloo L, Creighton P and O'Donovan M 2011. The economics of reseeding on a dairy farm. Irish Journal of Agricultural and Food Research 50, 113-122.

Shalloo L, Cromie A and McHugh N 2014. Effect of fertility on the economics of pasture based dairy systems. Animal 8 (suppl. 1), 222-231.

Shalloo L, Dillon P, Rath M and Wallace M 2004. Description and validation of the Moorepark dairy system model. Journal of Dairy Science 87, 1945-1959.

Shalloo L, O'Donnell S and Horan B 2007. Profitable dairying in an increased EU milk quota scenario exploiting the freedom to milk. In Proceedings of the National Dairy Conference Castlebar, 22 November 2007, Kilkenny, Ireland, pp. 20-45.

Shalloo L, O'Leary N, McDonagh A, Geoghegan A, Werner J and Leso L 2018. Big data and smart technologies in grassland research and grassland management. In Proceedings of the European Grassland Federation conference, June 2018, Cork, Ireland, 789-806.

Sibanda M, Mutanga 0 and Rouget M 2016. Comparing the spectral settings of the new generation broad and narrow band sensors in estimating biomass of native grasses grown under different management practices. GIScience and Remote Sensing 53, 614-633.

Spoliansky R, Edan Y, Parmet Y and Halachmi I 2016. Development of automatic body condition scoring using a low-cost 3-dimensional Kinect camera. Journal of Dairy Science 99, 7714-7725.

Steeneveld W, Hogeveen H and Oude Lansink AGJM 2015. Economic consequences of investing in sensor systems on dairy farms. Computers and Electronics in Agriculture 119, 33-39.

Steeneveld W, Rutten CJ, Oude Lansink A and Hogeveen H 2017. Why not investing in sensors is logical for dairy farmers. In Proceedings of the European Conference on Precision Livestock Farming'17, Nantes, France, pp. 55-64.

Taube F, Gierus M, Hermann A, Loges R and Schönbach P 2014. Grassland and globalization - challenges for north-west European grass and forage research. Grass Forage Science 69, 2-16.

Tullo E, Fontana I, Gottardo D, Sloth KH and Guarino M 2016. Technical note: validation of a commercial system for the continuous and automated monitoring of dairy cow activity. Journal of Dairy Science 99, 7489-7494.

Ungar E, Nevo Y, Baram H and Arieli A 2017. Evaluation of the IceTag leg sensor and its derivative models to predict behaviour, using beef cattle on rangeland. Journal of Neuroscience Methods 300, 127-137.

Van De Gucht T, Saeys W, Van Nuffel A, Pluym L, Piccart K, Lauwers L, Vangeyte $J$ and Van Weyenberg S 2017. Farmers' preferences for automatic lameness-detection systems in dairy cattle. Journal of Dairy Science 100, 5746-5757.

Van den Pol-van Dasselaar A, Becker T, Botana Fernández A, Hennessy T and Peratoner G 2018. Social and economic impacts of grass based ruminant production. In Proceedings of the European Grassland Federation General Meeting, Grassland Science in Europe, Sustainable meat and milk production from grasslands, 17-21 June 2018, Cork, Ireland, pp. 697-708.

Veerkamp RF, Dillon P, Kelly E, Cromie AR and Groen AF 2002. Dairy cattle breeding objectives combining yield, survival and calving interval for pasture based systems in Ireland under different milk quota scenarios. Livestock Production Science 76, 137-151.

Viazzi S, Bahr C, Van Hertem T, Schlageter-Tello A, Romanini C, Halachmi I, Lokhorst C and Berckmans D 2014. Comparison of a three-dimensional and two- 
dimensional camera system for automated measurement of back posture in dairy cows. Computers and Electronics in Agriculture 100, 139-147.

Werner J, Leso L, Umstatter C, Niederhauser J, Kennedy E, Geoghegan A, Shalloo

L, Schick M and O'Brien B 2017. Evaluation of the RumiWatchSystem for measuring grazing behaviour of cows. Journal of Neuroscience Methods 300, 138-146.

Williams ML, Mac Parthaláin N, Brewer P, James WPJ and Rose MT 2016. A novel behavioral model of the pasture based dairy cow from GPS data using data mining and machine learning techniques. Journal of Dairy Science 99, 2063-2075.
Wolfert S, Ge L, Verdouw C and Bogaardt MJ 2017. Big data in smart farming a review. Agricultural Systems 153,69-80.

Wolfger B, Jones BW, Orsel K and Bewley JM 2017. Technical note: evaluation of an ear-attached real-time location monitoring system. Journal of Dairy Science 100, 2219-2224.

Zehner N, Umstätter C, Niederhauser JJ and Schick M 2017. System specification and validation of a noseband pressure sensor for measurement of ruminating and eating behavior in stable-fed cows. Computers and Electronics in Agriculture 136, 31-41. 